\title{
An evaluation of factors influencing perceptual experiences and future plans of final-year medical interns in the Free State, 2013-2014
}

\author{
N Mofolo ${ }^{a *}$ iD and J Botes ${ }^{a}$ iD \\ ${ }^{a}$ Faculty of Health Sciences, Department of Family Medicine, University of the Free State, Bloemfontein, South Africa \\ *Corresponding author, email: mofolon@ufs.ac.za
}

\begin{abstract}
Background: Medical internship refers to the 24-month period of supervised training in an accredited facility, where newly qualified doctors rotate through all relevant medical domains before starting their community service as medical practitioners. The Free State province has one academic complex and three regional hospitals accredited for internship training.

Objectives: To evaluate the experience and future plans of final-year interns enrolled in a two-year medical internship programme in the Free State, and whether they felt sufficiently prepared to be medical doctors.

Methods: This study was a cross-sectional study. A questionnaire was distributed to all consenting interns from the Free State completing their second year of internship during 2013 and 2014.

Results: A total of 80 second-year internship doctors from four healthcare facilities completed the questionnaire. The majority (87.2\%) indicated that they believe internship prepared them well for community service and $65.0 \%$ were positive about the supervision they received. However, only $52.5 \%$ felt that they were properly orientated.

Conclusion: Medical interns felt positive about their experiences at their allocated Free State healthcare facilities and acknowledged they were better prepared for their careers. In some domains, insufficient supervision and lack of orientation impacted on the internship experience. Workload, lack of resources, insufficient staff and work environment at institutions are the main push factors.
\end{abstract}

Keywords: experiences, Free State, medical internship, professional development, push-and-pull factors, supervision, training

\begin{abstract}
Introduction
Medical internship refers to the period of supervised training for newly qualified doctors at an accredited facility such as a hospital, clinic or health centre. ${ }^{1}$ This is a transition period from being a student to becoming a professional. Medical internship should provide opportunities to further develop interns' knowledge, skills, appropriate behaviour patterns and professional thinking. During this time, interns should gain insight, understanding and experience in patient care to function as competent and safe medical practitioners. ${ }^{1,2}$
\end{abstract}

In South Africa, medical internship was introduced in 1950 as a one-year training period, rotating through specialist and subspecialist departments. The lack of practical competency, uniformity in training and relevance became a serious cause for concern and modifications were made early in the new millennium. ${ }^{2,3}$ In 2004, the two-year internship training programme was introduced, which included four-month rotations in the following key medical domains: general (internal) medicine, general surgery, obstetrics and gynaecology, paediatrics, family medicine ( 3 months) and psychiatry (1 month), and anaesthesiology (2 months) and orthopaedics (2 months). ${ }^{3,4}$ Training is comprehensive and complementary to the South African healthcare system with an emphasis on primary health care.

South Africa, like many countries in the world, has a massive shortage of medical practitioners due to insufficient production, management and retention. The distribution between the public and private sector in health care is also disproportionate due to the serious burden of disease and continuous migration of expertise and skills. ${ }^{5}$ Prinsloo, however, cautioned that the twoyear internship should not be seen as filling this gap in the workforce. $^{6}$
A few studies have been done in South Africa on the effectiveness and experience of the two-year internship programme. In a 2008 study done at a regional hospital in North West, Sein and Tumbo identified several factors that influence effective medical intern training including adequate opportunity for experiential learning, a conducive environment, reasonable workload, personal attributes, good support system and effective supervision from good quality supervisors. ${ }^{2}$ A similar study done in the Western Cape looked at factors influencing the development of practical skills of interns working in regional hospitals. The study underscored the importance of procedural skills development during internship, which needs to take place under sufficient supervision.?

In KwaZulu-Natal, community service medical officers were asked to evaluate their medical internship. Most of the respondents (78\%) were satisfied with their training. They felt confident in their acquired knowledge and skills in most disciplines, but gaps were recognised in Paediatrics, Anaesthetics, Orthopaedics and Obstetrics. ${ }^{8}$ Looking at basic surgical skills acquired in Gauteng and Mpumalanga, researchers found that, although the majority of interns from urban areas felt adequately skilled for Caesarean sections, lump excisions and the drainage of abscesses, core surgical skills were unsatisfactory. In comparison, semi-urban interns rated themselves sufficiently skilled in core surgical skills. ${ }^{9}$

In 2015, a national survey of 150 doctors who recently completed their internship was published. Feedback showed a serious lack of supervision. This was further worsened by workload issues and a lack of learning opportunities. Casualty and Family Medicine were rated low in regard to the frequency of teaching sessions. Only $22.2 \%$ of the participants believed that patients 
were never in danger while under their care, which they mostly considered the result of lack of supervision. Thus, compliance with Health Professions Council of South Africa (HPCSA) rules was not adequate. ${ }^{10}$

In the Free State during 2013 and 2014, the HPCSA accredited internship training sites, which included one academic hospital (accredited for 106 interns) and three regional hospitals (accredited for 20 interns each). Each accredited training facility is expected to have an intern curator to look after the interns' welfare. Facilities are also required to offer acceptable accommodation for interns, as needed. ${ }^{1}$

Internationally, health care is experiencing a severe staff shortage, of both doctors and nurses, especially in primary health care. One major reason is seemingly the preference of doctors to progress to a specialist field. The main factors identified in international studies for not choosing primary health care are remuneration, lack of prestige, not being in an academic/research environment, job security, workload and working hours. ${ }^{11-13}$

Another problem experienced worldwide and locally is the lack of doctors willing to work in rural areas. In an attempt to increase rural primary health care doctors, medical schools have increased the number of students from these catchment areas. ${ }^{14} \mathrm{~A}$ recent survey in Asia and Africa indicates that extended placement in rural areas during undergraduate training could be a greater indicator for future rural doctors. ${ }^{15}$ Still, intention to become a rural doctor could and should be determined in the matric year during the selection process, as this has been proven to be a successful indicator. ${ }^{16}$

Medical brain drain, which refers to health-worker migration, is an issue facing most countries in the world. Developing and lowincome countries are hit especially hard due to the costs involved in training these professionals. ${ }^{17}$ Although some local studies indicate remuneration to have lessened as an important pull factor, especially after the corrective measure taken by the South African Department of Health in 2007 to even out the gap between the private and public sectors, other studies still show salaries as a top reason for migration. ${ }^{18}$ The HIV/AIDS epidemic, workload, work environment, security and racial tensions are all major push factors. ${ }^{17}$

The movement of doctors from primary health care (and especially rural areas) towards speciality, different provinces or even migration is also prominent in the Free State. In this project, the authors sought to determine how final-year medical interns in the Free State perceived their internship. This would help identify 'push and pull' factors, ${ }^{19,20}$ and by so doing help management make strategic decisions in retention and recruitment of doctors in the Free State. These 'push-and-pull' factors are those elements which make physicians decide to remain in the local environment or continue their careers elsewhere.

\section{Objective}

To evaluate the factors influencing the perceptual experience of final-year medical interns enrolled in a two-year medical internship programme at four healthcare facilities in the Free State.

\section{Methods}

This was a cross-sectional study conducted at four HPCSA accredited internship training sites in the Free State. These included one academic hospital complex and three regional hospitals. The target population included all 2013 and 2014 finalyear medical interns completing their two-year internship in the Free State, irrespective of origin or tertiary institution. A total of 111 final-year medical interns were allocated to the four training sites in the Free State during that period. Nationally, 1130 and 1210 final-years completed their internship in 2013 and 2014, respectively.

Data were collected by means of a self-administered questionnaire, which was developed after a literature review, and questions were formulated to be in line with the objective of the study. The questionnaire contained four sections: demographic information; review of the interns' experiences during internship; their future plans; and working as an intern in the Free State.

Questions evaluating the experiences included five-point Likerttype scale questions (strongly agree, agree, neutral, disagree and strongly disagree) and rating questions (from $1=$ worst to 10 = best). Open-ended qualitative-style questions were included to give the participants the opportunity to share their opinions on the experience. Five doctors were invited to complete the questionnaire to test the research tool in a pilot study, but no issues were reported.

Participating medical interns were requested to complete the questionnaire and return it to the researchers either by hand or via the intern curator of the healthcare facility. Data were captured electronically and analysed by a biostatistician. Results were summarised in frequencies and percentages, thus a descriptive analysis was used.

The study protocol [ECUFS 225/2012] was approved by the Ethics Committee of the Faculty of Health, University of the Free State, and permission to conduct the study was obtained from the Free State Department of Health. Participants were informed that participation in the study was voluntary and that data would be treated confidentially. All participants signed a consent form.

\section{Results}

Of the 111 final-year medical interns of 2013 and 2014, 80 participants consented and returned their questionnaires (response rate $72.1 \%$ ) over the two-year research period between 2013 and 2014, of which 58.8\% $(n=47)$ of the questionnaires were completed in 2013.

\section{Demographic data}

An equal number of males and females participated, of whom $61.3 \%(n=49)$ were unmarried. Participants'ages ranged from 24 to 46 years, with a median age of 26 years.

The highest percentage $(44.3 \% ; n=35)$ of participants obtained their basic medical degrees from the University of the Free State; $12.7 \%(n=10)$ from the University of Pretoria and University of Stellenbosch, respectively; and $8.9 \%(n=7)$ at a tertiary institution outside of South Africa. 


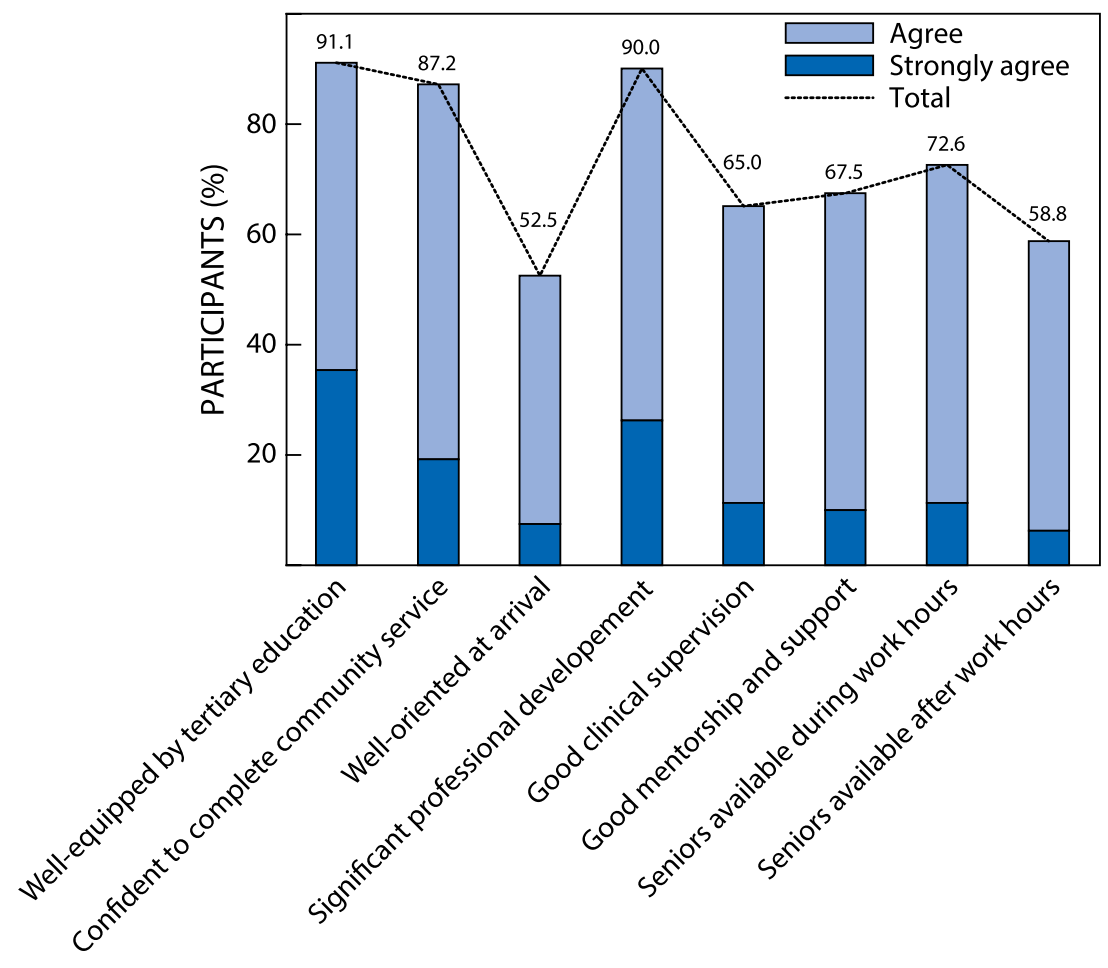

Figure 1: Percentage of interns reporting positive experiences from their medical internship at healthcare facilities in the Free State.

Three-quarters $(75.0 \% ; n=60)$ of participants were allocated to their first-choice facility, and $87.3 \%(n=69)$ were satisfied with the allocation process. The majority $(48.8 \% ; n=39)$ of the participating interns were placed at the Bloemfontein Academic Complex. The main reason for choosing the specific facility was to be close to family or friends $(32.4 \% ; n=25)$, while $12.1 \%(n=9)$ stated their choice was influenced by the academic set-up and support of the healthcare facility. Even though only two participants mentioned a bursary as a reason for their choice of placement, we delved further into the possible financial reasons; $33.3 \%(n=26)$ stated they have provincial bursary obligations with a median of 4.5 years of service to fulfil. Of these, $80.0 \%$ ( $n=$ 20) were determined to fulfil their bursary obligations, while the remaining $20.0 \%(n=5)$ intend to do a combination of service and payout.

\section{Review of internship years}

As shown in Figure 1, 90.1\% $(n=72)$ of interns were satisfied with their professional development, and $87.2 \%(n=68)$ felt sufficiently prepared for their community service year.

Comparing the percentage of interns reporting positive experiences at the different healthcare facilities (Table 1) delivered noteworthy results. At three of the healthcare facilities interns felt that they were sufficiently equipped for their internship by their undergraduate training institutions, well prepared for their community service year, and that they have experienced significant professional development.

Participants were requested to rate out of 10 each department at which they rotated. The authors categorised the scores as 'poor' (1-4), 'neutral' (5-6) and 'good' (7-10). As presented in Figure 2, the participants rated Anaesthesia (85.1\%; $n=63)$, Obstetrics and Gynaecology $(83.6 \% ; n=61)$ and Internal Medicine $(82.9 \% ; n$ $=58$ ) very highly. Family Medicine and Orthopaedics (both $58.7 \% ; n=44$ ) were rated less favourably.
Good supervision and orientation $(28.6 \% ; n=20)$ and quality of teaching and training $(18.6 \% ; n=13)$ were listed as reasons why participants rated a domain well. Other reasons for positive feedback included 'good clinical exposure' (8.6\%; $n=6$ ), 'opportunities to practise acquired skills' $(7.1 \% ; n=5)$, and 'good consultants/senior medical officers willing to teach and encourage' $(7.1 \% ; n=5)$.

With the worst rated domains, interns listed poor supervision $(20.6 \% ; n=15)$, workload $(9.6 \% ; n=7)$ and poor management at the healthcare facility $(9.6 \% ; n=7)$ as reasons. For these lower rated domains the participants suggested the appointment of more consultants and senior personnel (20.9\%; $n=14)$, improvement of the supervision $(11.9 \% ; n=8)$, and better organisation $(6 \%, n=4)$.

The majority of interns $(73.4 \% ; n=58)$ rated the relationship with the intern curator as good, while $21.5 \%(n=17)$ felt indifferent.

Despite a few worrying cases $(n=4)$, most interns felt they coped well $(77.6 \% ; n=62)$ and were positive about their upcoming community service year $(81.8 \% ; n=63)$ (Table 2 ). Self-importance was also evident in the open-ended remark section where participants stated that they worked hard and provided a good service, while other remarks ranged from filling in when medical officers were not available, to feeling they went out of their way to ensure patients' well-being. Unfortunately there were a few discouraged interns who mentioned that they felt as if they barely made a difference due to the massive burden.

Regarding remuneration, $75.9 \%(n=60)$ of the interns were satisfied, while $3.8 \%(n=3)$ disagreed. Most $(73.8 \% ; n=59)$ agreed that salaries and allowances were received on time.

Only $30.0 \%(n=24)$ of the participants had the opportunity to register and study towards additional training or qualification 
Table 1: Experiences of medical interns in the Free State per healthcare facility $(n=80)$

\begin{tabular}{|c|c|c|c|c|}
\hline Statement & 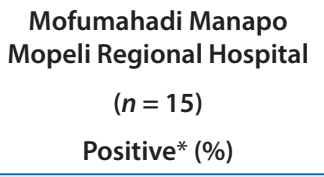 & $\begin{array}{c}\text { Bloemfontein Academic } \\
\text { Complex } \\
(n=39) \\
\text { Positive }^{*}(\%)\end{array}$ & $\begin{array}{l}\text { Bongani Regional Hospital } \\
\qquad \begin{array}{c}(n=14) \\
\text { Positive* }(\%)\end{array}\end{array}$ & $\begin{array}{c}\text { Dihlabeng Regional } \\
\text { Hospital } \\
(n=12) \\
\text { Positive* }(\%)^{\text {(n) }}\end{array}$ \\
\hline $\begin{array}{l}\text { My tertiary education } \\
\text { equipped me well for my } \\
\text { internship year }\end{array}$ & 92.9 & 94.9 & 92.9 & 75.0 \\
\hline $\begin{array}{l}\text { I am confident that my intern- } \\
\text { ship has prepared me well to } \\
\text { do my community service year }\end{array}$ & 100.0 & 87.2 & 69.2 & 91.7 \\
\hline $\begin{array}{l}\text { I was well orientated to my } \\
\text { job by the hospital staff when } \\
\text { I arrived }\end{array}$ & 66.7 & 56.4 & 35.7 & 41.7 \\
\hline $\begin{array}{l}\text { I have experienced significant } \\
\text { professional development } \\
\text { during my internship }\end{array}$ & 93.3 & 92.3 & 71.4 & 100.0 \\
\hline $\begin{array}{l}\text { I have experienced good } \\
\text { clinical supervision during my } \\
\text { internship }\end{array}$ & 53.3 & 79.5 & 57.1 & 41.7 \\
\hline $\begin{array}{l}\text { I have experienced good men- } \\
\text { torship and support during my } \\
\text { internship }\end{array}$ & 60.0 & 79.5 & 57.1 & 50.0 \\
\hline $\begin{array}{l}\text { My seniors have always been } \\
\text { available when I needed help } \\
\text { during working hours }\end{array}$ & 73.3 & 82.1 & 64.3 & 50.0 \\
\hline $\begin{array}{l}\text { My seniors have always been } \\
\text { available when I needed help } \\
\text { after work hours }\end{array}$ & 40.0 & 69.2 & 57.1 & 50.0 \\
\hline
\end{tabular}

*Positive $=$ strongly agree and agree.

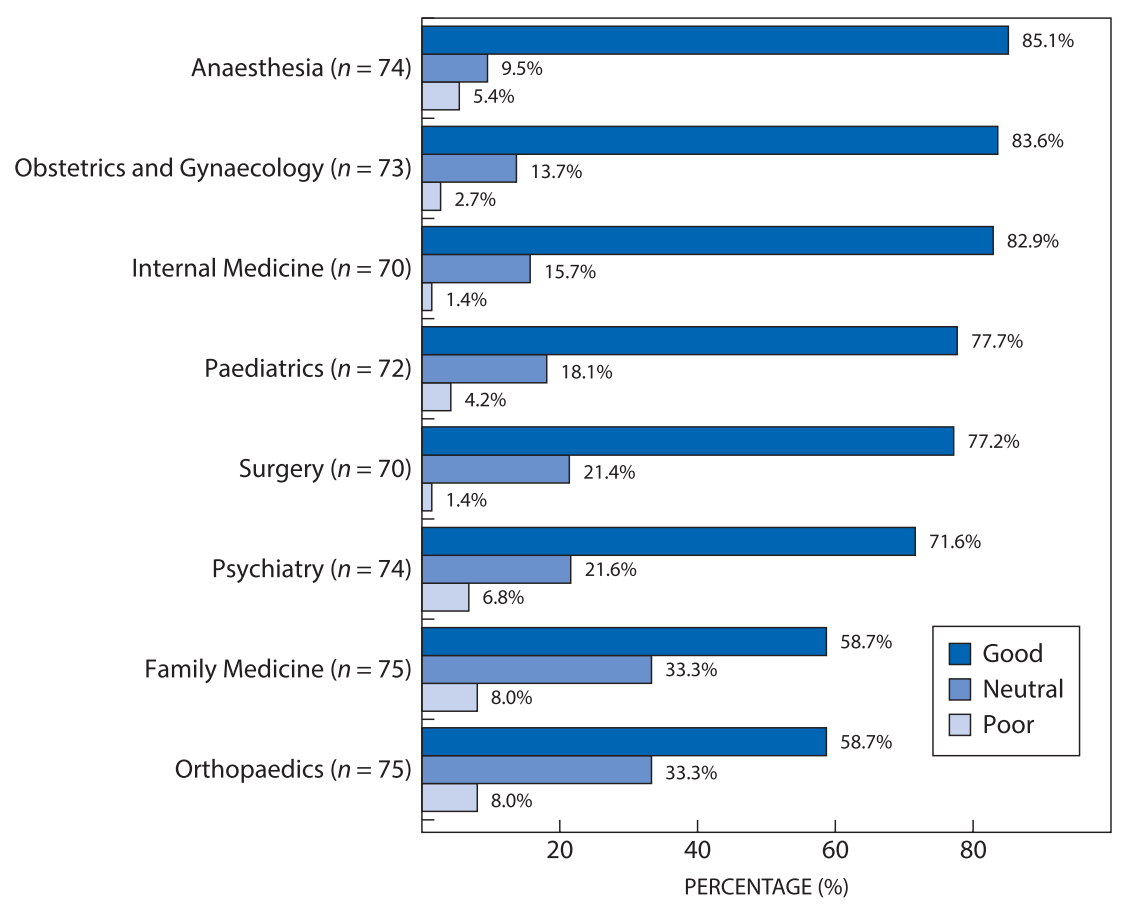

Figure 2: Ratings of different domains according to education, training, supervision, support and organisation.

during their internship, stating the lack of study leave $(44.1 \% ; n=26)$ and not receiving information or guidance about learning opportunities $(20.3 \% ; n=12)$ as the main issues. The courses completed included Essential Steps in Managing Obstetric Emergencies (ESMOE), Advanced Clinical Life Support (ACLS), Basic Life Support (BLS) and Advanced Trauma Life Support (ATLS).
When asked about the average number of overtime hours per week, the median was at 20 hours, which is within the acceptable limits of the law. There were a few responses of up to 45 hours, but it may be that some participants reported their hours per month, rather than per week. 
Table 2: Perceived psychological impact of internship as reported by the medical interns

\begin{tabular}{lccccc}
\hline Factor & $\begin{array}{c}\text { Strongly } \\
\text { agree } \\
n(\%)\end{array}$ & Agree & Neutral & Disagree & $\begin{array}{c}\text { Strongly } \\
\text { disagree }\end{array}$ \\
& $n(\%)$ & $n(\%)$ & $n(\%)$ & $n(\%)$ \\
\hline $\begin{array}{l}\text { Coped well } \\
\text { psychologically } \\
\text { during intern- } \\
\text { ship (mental } \\
\text { health) (n=80) }\end{array}$ & $15(18.8)$ & $47(58.8)$ & $14(17.5)$ & $3(3.8)$ & $1(1.3)$ \\
$\begin{array}{l}\text { Feel positive } \\
\text { about commu- } \\
\text { nity service the } \\
\text { following year } \\
\text { (motivation) } \\
\text { (n=77) }\end{array}$ & $15(19.5)$ & $48(62.3)$ & $12(15.6)$ & $2(2.6)$ & $0(0)$ \\
$\begin{array}{l}\text { Feel that he/ } \\
\text { she contributed } \\
\text { significantly to } \\
\text { the health of } \\
\text { the community } \\
\text { (self-impor- } \\
\text { tance) (n=80) }\end{array}$ & $24(30.0)$ & $46(57.5)$ & $9(11.3)$ & $1(1.3)$ & 0 \\
\hline
\end{tabular}

Where accommodation was provided, $44.8 \%(n=30)$ of the participants felt content, while $20.9 \%(n=14)$ were dissatisfied with the conditions provided by the healthcare facility.

While $31.7 \%$ ( $n=25$ ) felt there was no serious risk to their personal safety, $35.4 \%(n=28)$ believed there was an increased risk during their internship. This is further supported in that $53.9 \%(n=42)$ required post-exposure prophylaxis due to potentially infectious incidents.

Only $27.6 \%(n=21)$ of the participants felt management handled their problems or concerns satisfactorily, while $19.7 \%(n=15)$ felt aggrieved by the handling of their cases.

More than half $(53.2 \% ; n=42)$ of the interns would recommend the healthcare facility where they completed their medical internship to future interns, while $31.7 \%(n=25)$ were unsure. Comments were diverse in their reasoning; positive remarks included good training and practical experiences, while negative remarks noted lack of medical officers, difficult working relations, poor service from management, and the poor accommodation experienced by some.

\section{Future plans}

A total of $69.6 \%(n=55)$ of the interns indicated that the internship experience changed their long-term career plans, while $22.8 \%(n=18)$ were neutral. Disappointingly, $62.3 \%$ ( $n=$ 48) showed no interest in working at the same institution during their community service, while $16.8 \%(n=13)$ were indecisive. The most important factor for their decisions on where to work the following year was family responsibilities $(40.7 \%, n=31)$.

From those planning on doing their community service outside the Free State $(52.5 \%, n=42)$, the majority $(64.3 \%, n=27)$ made the decision during their internship period. Only $10.8 \%(n=8)$ intended to leave the public sector after completing their community service year, while $46.0 \%(n=34)$ were still unsure.

Many $(39.5 \%, n=30)$ had future plans for securing a job overseas, while $36.8 \%(n=28)$ were still unsure. Half $(50.0 \%, n=15)$ of those planning an overseas career considered Canada a good option, while $20.0 \%(n=6)$ had their sights set on the United Kingdom. When asked how long they intended to stay overseas, half $(50.0 \%, n=15)$ did not consider staying longer than two years, and $26.6 \%(n=8)$ planned for a four- to five-year stint. Only one participant indicated permanent emigration.

Most $(93.4 \%, n=71)$ had full intentions of continuing in the medical profession, while five $(6.6 \%)$ indicated plans to cut their medical careers short. Only one indicated his experience during internship to be the causative factor.

Regarding future studies, $86.8 \%(n=66)$ were planning to continue training after their community service. Of these, $63.6 \%$ $(n=42)$ planned to specialise. The fields of study specified varied widely with no prominent field standing out, although the areas most frequently mentioned were surgery, anaesthesia, emergency medicine and gynaecology.

Rural areas tend to pull very few medical professionals, but in this study $35.5 \%$ ( $n=27)$ planned to work in a rural or underserved area within South Africa. Many $(43.4 \%, n=33)$ were still uncertain. Those who had no interest stated 'better schools for kids in the city', 'poor resources' and 'poor working conditions' as reasons.

\section{Working as medical interns in the Free State}

In an open-ended question, participants were asked to state what they enjoyed most about internship in the Free State. Positive aspects stated included 'great experience and learning opportunities,',close to family', and 'friendly people'. The negative aspects included 'lack of resources', 'limited social life', 'staff shortages', 'language issues', and 'financial limitations at hospitals'.

Participants were requested to select factors that they consider most influential in healthcare professionals' decision to leave the province and/or South Africa. Working conditions were the highest ranked factor with 61 (76.2\%) participants adding this to their top five list. This was also the top first-ranked factor for $50.8 \%(n=31)$. The following factors were also mentioned as most influencing factors: 'work overload' $(55.0 \%, n=44)$, 'availability of equipment' $(50.0 \%, n=40)$,'being underappreciated' $(41.2 \%, n=33)$ and 'insufficient staff' $(41.2 \%, n=33)$.

Improved working conditions, appointing more personnel to relieve the workload, and better management of resources were the recommendations made by participants that they felt would convince healthcare professionals to stay in the Free State.

\section{Discussion}

\section{Review of internship years}

Most of the interns felt adequately equipped for their community service period. This is a good indication that the Free State Department of Health is succeeding in the quality of the internship training programme provided.

An area of concern is the orientation process. Only $52.5 \%(n=42)$ of participants stated they were sufficiently orientated at the beginning of their medical internship. This is an issue that could be easily rectifiable through better planning and more efficient communication between staff. Interns should not be left to their own devices as professional development should be initiated immediately; this cannot occur when interns are unsure about their role, supervision and how services operate at their training site. Furthermore, the interns' effectiveness as capable medical workers may be limited until they feel comfortable within their environment. 
All three regional hospitals displayed less positivity regarding the mentorship and supervision. Bongani Regional Hospital scored the lowest in preparing interns for their community service year, which could directly be linked to the lack of orientation, supervision and mentorship. Dihlabeng Regional Hospital scored low on good clinical supervision, good mentorship and support and availability of seniors during working hours, but the medical interns still felt confident in their own abilities. Both Universitas Academic Complex and Mofumahadi Manapo Mopeli Regional Hospital rated well in preparation for community service and professional development. Mofumahadi Manapo Mopeli Regional Hospital also rated low on supervision and availability of seniors, even though a $100 \%$ confidence rating was reported.

Although confidence is important in preparation for community service, institutions should be wary of using confidence as a measurement tool. Self-assessment does not always reflect well on actual knowledge and ability. ${ }^{20}$ Considering the insufficient supervision, the lack of assessment and feedback may have led to false confidence. Unfortunately, this study did not measure actual competence, and this issue should be considered in future projects.

Even with that in mind, one should be careful of comparing supervision and mentorship between hospitals, since this is a measurement of a perceived experience versus the preconceived expectation of the chosen facility. Expectations of supervision at academic complexes, regional urban complexes and rural-based hospitals may vary broadly. The most important aspects to take from these results are insufficient orientation and supervision. This is unfortunately in line with other relevant studies done in South Africa. ${ }^{10}$

Jaschincki and De Villiers ${ }^{7}$ also found in their study in the Western Cape that interns consider good support and supervision an important factor for their development. They noted that, even though many medical interns prefer some independence to build confidence, it is reassuring to know there is a knowledgeable senior person to consult.

\section{Future plans}

The internship period in the Free State has an obvious effect on the future plans of medical professionals, as most planning to leave the province made the decision during their rotations. Very few interns were positive about remaining at the current institution. As seen in most developing countries, many of the interns are planning a career abroad, even if only for a short period.

The majority of the interns are planning further studies, of whom most plan to specialise. The internship did not succeed in pulling primary health care doctors, which is also evident in the low ranking of Family Medicine. A positive aspect is the number of interns planning a career in rural areas. Although it is unlikely that most of these participants will follow through, it is encouraging to see that junior doctors still consider this a possibility.

\section{Working as interns in the Free State}

The main push factors interpreted from the results include workload, lack of resources, lack of staff, and financial mismanagement at hospitals. Participants felt that if these factors could be improved on or resolved, the Free State would be a more attractive destination for both medical internship and beyond.

\section{Study limitations}

Due to the neutral option in the Likert-scale questions, the results of the study may have been influenced by interns not committing to rating an experience as either positive or negative. The responses of the medical interns may also have been affected by their emotional status at the time of study participation and the rotation taking place when they were completing the questionnaire.

\section{Conclusions and recommendations}

In general, medical interns are quite satisfied with their internship experience at healthcare facilities in the Free State, as well as their self-assessed professional development. The majority of the interns are content with the level of supervision in their training. In that respect, the HPCSA requirements are being achieved.

However, healthcare facility management should consider steps to improve supervision, orientation and mentorship, which are essential to the internship according to the HPCSA's rules and regulations. Unless the interns' perception were skewed by their emotional status at that stage of their rotation, the level of supervision should not be considered sufficient. The Free State Department of Health should be aware of these deterrents, and determine how to improve on them.

Many of the interns want to pursue further studies, while some have plans to work abroad. A reasonable number indicated that they would like to stay in public service, but most of the interns are still undecided at the end of their internship on whether or not to serve rural communities.

This study indicates that medical interns' experience during their internship in the Free State healthcare facilities has the ability to influence their career path in the public sector. Better planning is required to make primary health care an attractive option.

This study needs to be ongoing and can be extrapolated to the community service year. Future studies should consider comparing before-and-after questionnaires to determine the changes in perceptions.

Acknowledgments - Ms T Mulder, medical editor, School of Medicine, University of the Free State, for technical and editorial preparation of the manuscript. The authors would like to acknowledge Dr Perpetual Chikobvu from the Research Unit of the Free State Department of Health for the statistical analysis of the data. The authors would like to thank Dr TD Moji, former Deputy Director General for Clinical Services from Free State Department of Health, for his support of the project. MrThabang Maseme, research assistant to Dr Mofolo at time of study, is thanked for his assistance in data collection at the various sites and assistance in capturing the data.

Conflict of interest - The authors declare that there were no conflicts of interest.

\section{References}

1. Medical and Dental Professions Board, Health Professions Council of South Africa. HPCSA internship guidelines 2012. Pretoria:HPCSA; 2012.

2. Sein NN, Tumbo J. Determinants of effective medical intern training at a training hospital in North West Province, South Africa. Afr J Health Prof Educ. 2012;4(1):10-4.

3. Meintjes Y. The 2-year internship training. S Afr Med J. 2003;93(5):336337.

4. Health Professions. Act 1974 (Act No 56 of 1974) Section 61(1) (e) Pretoria: Department of Health; 1974. 
5. George G, Quinlan T, Reardon C, et al. Where are we short and who are we short of? A review of the human resources for health in South Africa. Health SA Gesondheid. 2012;17(1):1-7. doi:10.4102/hsag. v17i1.622.

6. Prinsloo EAM. Editorial: a two-year internship programme for South Africa. SA Fam Pract. 2005;47(5):3. doi: 10.1080/20786204.2005.10873222.

7. Jaschinski J, De Villiers MR. Factors influencing the development of practical skills of interns working in regional hospitals of the Western Cape Province of South Africa. SA Fam Pract. 2008;50(1):70-70d. doi: 10.1080/20786204.2008.10873676.

8. Nkabinde TC, Ross A, Reid S, et al. Internship training adequately prepares South African medical graduates for community service - with exceptions. S Afr Med J. 2013;103(12):930-34. doi:10.7196/ samj.6702. PMID: 24300632

9. Peters FM, Van Wyk JM, Van Rooyen M. Intern to independent doctor: basic surgical skills required for South African practice and interns' reports on their competence. SA Fam Pract. 2015;57(4):261-266. doi: 10.1080/20786190.2014.976954.

10. Bola S, Trollip E, Parkinson F. The state of South African internships: A national survey against HPCSA guidelines. S Afr Med J. 2015;105(7):535-39. doi: 10.7196/SAMJnew.7923.

11. Puertas EB, Arósquipa C, Gutiérrez D. Factors that influence a career choice in primary care among medical students from high-, middle-, and low-income countries: a systematic review. Rev Panam Salud Publica. 2013;34(5):351-58. PMID: 24553763.

12. Harris JE, González López-Valcárcel B, Ortún V, et al. Specialty choice in times of economic crisis: a cross-sectional survey of Spanish medical students. BMJ Open. 2013;3(2):e002051. doi:10.1136/ bmjopen-2012-002051. PMID: 23408072.
13. Parker JE, Hudson B, Wilkinson TJ. Influences on final year medical students' attitudes to general practice as a career. J Prim Health Care. 2014;6(1):56-63. PMID: 24624412.

14. De Vries $E$, Reid S. Do South African medical students of rural origin return to rural practice? S Afr Med J. 2003;93(10):789-93. PMID: 14652974.

15. Clark TR, Freedman SB, Croft AJ, et al. Medical graduates becoming rural doctors: rural background versus extended rural placement. Med J Aust. 2013;199(11):779-82. doi:10.5694/mja13.10036.

16. Silvestri DM, Blevins M, Afzal AR, et al. Medical and nursing students intentions to work abroad or in rural areas: a cross sectional survey in Asia and Africa. Bull World Health Organ. 2014;92(10):750-59. doi: 10.2471/BLT.14.136051. PMID: 25378729.

17. Kollar E, Buyx A. Ethics and policy of medical brain drain: a review. Swiss Med Wkly. 2013;143:w13845. doi:10.4414/smw.2013.13845. PMID: 24163012.

18. George G, Atujuna M, Gow J. Migration of South African health workers: the extent to which financial considerations influence internal flows and external movements. BMC Health Serv Res. 2013;13:119. doi:10.1186/1472-6963-13-297. PMID: 23919539.

19. Kasper J, Bajunirwe F. Brain drain in sub-Saharan Africa: contributing factors, potential remedies and the role of academic medical centres. Arch Dis Child. 2012;97(11):973-79. doi:10.1136/ archdischild-2012-301900. PMID: 22962319.

20. Davis DA, Mazmanian PE, Fordis M, et al. Accuracy of physician selfassessment compared with observed measures of competence. JAMA. 2006;296(9):1094-1102. doi:10.1001/jama.296.9.1094. PMID: 16954489. 